\title{
Spatial Competition within Urban Areas: Hotelling and Bertrand Reconciled
}

\author{
Didier Baudewyns ${ }^{* \dagger}$
}

July, 2000

\begin{abstract}
In this paper, we assume the existence of a distribution of urban amenities having its maximum at the city center. These amenities are viewed as a surrogate for all kinds of outside opportunities that consumers encounter within urban areas. Using the Hotelling model, we study the impact of these amenities on independent location and pricing decisions of duopolists. Consumers patronize the firm where the amount of amenities is larger, ceteris paribus. If this demand externality is strong at the midpoint then minimum differentiation occurs without moderation of price competition, in contrast to mainstream results in the literature. For intermediate values of the ratio of transportation cost to spatial concentration of amenities, firms tacitly play an asymmetric equilibrium with one firm near (or at) the midpoint and its rival at a more suburban location. This causes intra-urban inequalities since some consumers are induced to patronize the decentralized marketplace where they encounter fewer urban life opportunities.
\end{abstract}

JEL Classification: D43, L11, R32.

Keywords: urban amenities, location-then-price equilibrium, minimum differentiation, asymmetric equilibria.

*Universidade Nova de Lisboa, Faculdade de Economia, Travessa Estêvão Pinto (Campolide), P-1099-032, LISBOA, Portugal. E-mail: dbaudewy@fe.unl.pt

${ }^{\dagger}$ I thank participants at EEA99, Santiago de Compostela and seminar participants at Universidade Nova, Faculdade de Economia, Lisboa. I thank Mathias Dewatripont, Victor Ginsburgh, Khalid Sekkat, Anouk Rivière and W.M. Kelly for their encouragements and their comments. 


\section{Introduction}

This paper deals with the location and pricing decisions made by oligopolistic firms within urban areas. Our starting point is the fact that people often make multipurpose trips, i.e. they make their decision to visit a particular place for several reasons such as the purchase of various private commodities, the consumption of a local public good (e.g. museum, park) and the social interactions with friends who happen to be there. ${ }^{1}$ Besides, it could simply be more agreeable to consume some specific goods or services, such as restaurants, in some areas characterized by nice sceneries or historical amenities which are aesthetically pleasing. It is easy to think of many neighborhoods in central Paris (e.g., the Quartier Latin) or entertainment districts in central London. The purpose of this paper is to combine all these facts into the spatial competition setting and to investigate their impact on oligopolistic firms' locations and prices.

Notice by the way that it has proven especially difficult to solve the multipurpose shopping problem, as shown by Quinzii and Thisse (1990). This is one of the reasons why we use in this paper a simplified shopping model in which the spatial distribution of other shopping and contact opportunities is given to consumers and to oligopolists. To make myself clear, I will assume the existence of urban amenities that individuals can jointly consume along with the good or service produced by one retailer in a duopoly. These amenities are to be viewed as a surrogate for the various outside opportunities, economic, cultural and social, that consumers encounter within urban areas. As a result, when they choose a marketplace to visit, consumers also account for the amount of amenities available in the vicinity of either stores. This implies that the demand to an oligopolistic firm at any location now depends on the amenity advantage of that location. Since urban amenities are more concentrated around the city center - at least in most European $\operatorname{cities}^{2}$ - , this will give an incentive to each duopolist to move toward the urban center.

Formally, we will add this centripetal force to the Hotelling model-more precisely, to the version proposed by d'Aspremont et al (1979). This model has been intensively used in the product differentiation literature but has been less successful in its genuine spatial interpretation. We argue that the

\footnotetext{
${ }^{1}$ For a survey of this literature, see Thill and Thomas (1987).

${ }^{2}$ See Brueckner, Thisse and Zenou (1998).
} 
main reason for this failure is precisely that urban economists have used this model without succeeding to capture demand externalities as described above. ${ }^{3}$ In this respect, we hope to show that the Hotelling model is a natural framework to analyze spatial strategic interactions of oligopolists, especially when they operate in an urban structure yielding demand externalities.

Our model is related to two different strands of literature. Firstly, Stahl $(1982,1987,1995)$ has shown that consumers' preference for variety and the existence of economies of scope in jointly purchasing many commodities on the same site, can induce producers to agglomerate. ${ }^{4}$ This approach of spatial demand externalities is indeed very fruitful; Hotelling-type spatial competition is assumed away but this is inconsequential for the results in Stahl (1982, $1987,1995)$ that hold for products that are not too close substitutes.

We will relax this assumption by referring to the second strand of literature: d'Aspremont et al (1979) and its extensions. D'Aspremont et al have formalized location and pricing decisions of duopolists as a noncooperative dynamic game. They have shown that duopolists tend to differentiate their locations in order to soften price competition in the last stage of the game. Other authors have tried to restore the so-called Hotelling's Principle of Minimum Differentiation. Some have assumed that goods contain inherent attributes (see de Palma et al, 1985) or unobservable attributes (see Rhee et al, 1992) so that price competition can be sufficiently relaxed. However, this approach moves away from the assumption that the good is homogenous as suggested by Hotelling himself. Jehiel (1992), and Friedman and Thisse (1993), have assumed that firms collude on price through punishment. This mechanism restores the minimum differentiation outcome but again, it moves away from the hypothesis that firms make their decisions independently. Zhang (1995) has restored the principle of minimum differentiation within a noncooperative location-then-price game by adding an intermediate stage of price matching policy. All competition for market shares is transferred to the leapfrog location game which ends up with a minimum differentiation of locations.

In contrast to these mainstream results, Mai and Peng (1999) have restored the principle of minimum differentiation without relaxing price competition. These authors introduce an element of cooperation between firms

\footnotetext{
${ }^{3}$ Another reason for it is also that conditions for the existence of an equilibrium in prices are seldom met for inside location games (see Gabszewicz and Thisse, 1992).

${ }^{4}$ Stahl establishes that the demands for two different commodities are complementary if they are sold on the same site, even if these commodities are Marshallian substitutes.
} 
in the form of information exchange through communication (about R\&D) into the location game. When spatial communication externalities are very large then price competition is relegated to a secondary effect to such an extent that agglomeration is a market equilibrium.

Yet, no attempt has been made to incorporate spatial demand externalities into the Hotelling model. We will mainly show that for a high concentration of urban amenities near the city center and a given low transportation cost, minimum differentiation occurs without any moderation of price competition. Indeed, should a duopolist choose a non-central location, he (or she) would face no demand, given that his (or her) rival is situated in the central area of the city. This strong spatial demand externality leads each firm to choose independently the central location in the first stage in order to secure half of the market. In this sense, by adding a more realistic urban structure to the assumptions suggested by Hotelling himself (homogenous product, noncooperative location-then-price game), our paper reconciles the Bertrand outcome and the principle of minimum differentiation in the context of spatial demand externalities. In contrast, in cities where transportation cost is relatively high and urban life less dense, then the classical dispersion effect dominates - that is duopolists differentiate their respective locations in order to relax price competition.

As opposed to Mai and Peng (1999), the profit of each firm does not increase with spatial proximity because there is no externality-like benefit from gathering on the same site. Moreover, the demand externality-i.e., the amenity effect in our model, modifies not only the location game but also the price game since it affects positively (negatively) the markup of the most centralized (decentralized) firm.

The remainder of the paper is organized as follows : section 2 presents the assumptions of the model. Section 3 solves the model for a distribution of amenities having its maximum at one end of the city. In section 4, we solve the model whenever the amenity distribution is triangular, symmetric about the midpoint. Section 5 analyzes the socially optimal locations from the welfare point of view. Some concluding remarks are given in section 6 .

\section{The model}

Our model closely follows the assumptions of d'Aspremont et al (1979) hereafter called the reference model. Consumers are uniformly distributed along 
a linear city with length 1 and bear a quadratic transportation cost. The population of consumers is normalized to one without loss of generality. As emphasized in the preceding section, we assume the existence of an exogenous distribution of outside opportunities: let $f(x)$ denote the level of urban amenities at location $0 \leq x \leq 1$. Two oligopolistic firms denoted $i=A, B$ produce a homogenous good or service at respective prices $p_{i}$ with an identical unit cost that is normalized to 0 (standard). The game is played in two stages. In the first stage both firms simultaneously choose their location, respectively $a$ and $1-b \in[0,1]$ with $1-b-a \geq 0$ without loss of generality (see figure 1). The last stage is the standard Bertrand price competition. Consumers value positively the amount of urban amenities available in the vicinity of either stores. The indirect utility of a consumer located at $x$ is given by

$$
U_{A}(x)=\bar{u}-p_{A}-t(x-a)^{2}+f(a)
$$

if she shops to $\mathrm{A}$ and consumes amenities $f(a)$,

$$
U_{B}(x)=\bar{u}-p_{B}-t(1-b-x)^{2}+f(1-b)
$$

if she shops to $\mathrm{B}$ and consumes amenities $f(1-b)$. The reservation price $\bar{u}$ is large enough to ensure that every consumer is served in any equilibrium (standard). The consumer who is indifferent between firm A and firm B resides at $\widehat{x}$ such that

$$
\widehat{x}=\frac{p_{B}-p_{A}}{2 t(1-b-a)}+\frac{1-b+a}{2}-\frac{f(1-b)-f(a)}{2 t(1-b-a)}
$$

after equalling (1) to (2). We can then write the demand for the product sold by firm $i(i=A, B)$ as follows:

$$
\begin{gathered}
D_{A}\left(p_{A}, p_{B} ; a, b\right)=\left\{\begin{array}{cr}
\widehat{x} & \text { if } 0<\widehat{x}<1, a \neq 1-b \\
0 & \text { if } \widehat{x} \leq 0, a \neq 1-b \\
1 & \text { if } \widehat{x} \geq 1, a \neq 1-b \\
\frac{1}{2} & \text { if } a=1-b
\end{array}\right. \\
D_{B}\left(p_{A}, p_{B} ; a, b\right)=1-D_{A}\left(p_{A}, p_{B} ; a, b\right)
\end{gathered}
$$

Next, respective profits are as follows:

$$
\Pi_{i}\left(p_{A}, p_{B} ; a, b\right)=p_{i} D_{i}\left(p_{A}, p_{B} ; a, b\right) \quad i=A, B
$$


Suppose for the moment that each firm expects that it will face a positive demand at dispersed locations. Then, for fixed locations, let $P_{i}\left(p_{j}\right)$ denote the best response of firm $i$ to a price $p_{j}$ set by its rival. First-order conditions for profit maximization lead to the following system of equations which must prevail in any equilibrium of the location-then-price game:

$$
\begin{aligned}
& P_{A}\left(p_{B}\right)=\frac{p_{B}}{2}+\frac{f(a)-f(1-b)+t(1-b+a)(1-b-a)}{2} \\
& P_{B}\left(p_{A}\right)=\frac{p_{A}}{2}+\frac{f(1-b)-f(a)+t(1+b-a)(1-b-a)}{2}
\end{aligned}
$$

In stark opposition to the reference model, for some values of $t$ relatively to $f(1-b)-f(a)$, these price functions are not valid since they imply a zero-demand for the most decentralized firm, even if the latter firm prices at marginal cost. ${ }^{5}$

In the rest of the paper, we will assume that the amenity distribution is successively linear, upward sloping on $[0,1]$ (section 3 ), and triangular symmetric about the midpoint (section 4). Accordingly, in each set-up, the model is solved in several stages, each of them corresponding to a certain range of the slope of the amenity distribution relative to the transportation cost parameter. I retain these two distributions because they easily capture the idea of amenity concentration about one point. ${ }^{6}$ All the mathematical developments are relegated to the appendix of Baudewyns (2000), section 10.

\section{Asymmetric triangular distribution of ameni- ties}

Let us first consider a triangular amenity distribution having its maximum at the east end of the city (see figure 1):

$$
f(x)=\left(1-\frac{\alpha}{2}\right)+\alpha x \quad \forall x \in[0,1], 0<\alpha<2
$$

\footnotetext{
${ }^{5}$ For example, imagine $f(1-b)-f(a)$ so large that $\widehat{x}<0$ even if firm A is close to $\mathrm{B}$ and prices at marginal cost. Notice by the way in this example that, for $a=1-b$, we have $D_{A}=\frac{1}{2}$, i.e., demand functions that are not continuous at $a=1-b$. Yet, the location-then-price game remains well-behaved, as we make clear in the next sections.

${ }^{6}$ For non-linear distributions of amenities, the location game becomes more intricate (or even not tractable) but we think that the main conclusions would remain unchanged. Yet, notice that the price game is solved in the appendix for any amenity distribution that is continuous and symmetric.
} 


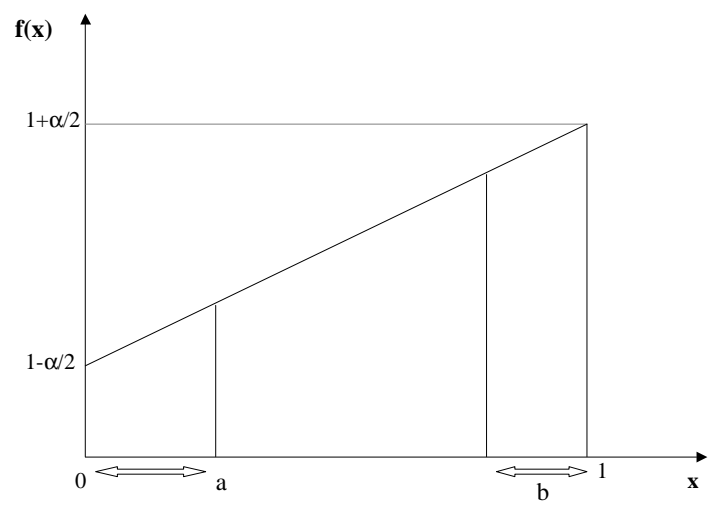

Figure 1: Asymmetric triangular distribution of urban amenities

so that $f(x)>0$ for any $x \in[0,1]$ and the total cumulative distribution of amenities is normalized to $1 .^{7}$ One can think of a port city where the amount of outside opportunities is maximum at the east end, near the port. Using (9) and substituting for $f(a)$ and $f(1-b)$ into (3), one obtains the following expression:

$$
\widehat{x}=\frac{p_{B}-p_{A}}{2 t(1-b-a)}+\frac{1-b+a}{2}-\frac{\alpha}{2 t}
$$

The higher the slope of the amenity distribution $(\alpha)$, the higher the demand to firm B, because it benefits from a better local environment in terms of urban amenities. For expositional purposes, let us introduce some definitions: by analogy with Combes and Linnemer (2000), B will be called the dominant firm because it benefits from more demand externalities. We will also say that an equilibrium is fully dispersed if each firm locates at one different end of the line. The following proposition characterizes all the pure-strategy subgame perfect equilibria (SPE) of the location-then-price game:

Proposition 1 If the distribution of amenities is linear, strictly increasing in $x$ on $[0,1]$ then, for any $\frac{t}{\alpha}$, there exists a unique SPE in which the dominant firm locates at the east end of the city: $b^{*}=0$. Moreover,

\footnotetext{
${ }^{7}$ This normalization is stronger than necessary but it allows us to compare results in this section to the results of the symmetric triangular set-up (next section).
} 
(i) if $\frac{t}{\alpha} \leq \frac{1}{4}$ then firm $A$ also locates itself at the east end of the line: $a^{*}=1$ (full agglomeration). Equilibrium prices and demands are as follows: $p_{A}^{*}=p_{B}^{*}=0, D_{A}^{*}=D_{B}^{*}=\frac{1}{2}$.

(ii) if $\frac{1}{4}<\frac{t}{\alpha}<1$ then the equilibrium is partially dispersed: $0<a^{*}=$ $\frac{\alpha}{3 t}-\frac{1}{3}<1$. As $\frac{t}{\alpha} \rightarrow \frac{1}{4}$, although firm A gets closer to firm B, it attracts less and less consumers: $D_{A}^{*} \rightarrow 0$.

(iii) if $\frac{t}{\alpha} \geq 1$ then firm $A$ locates at the west end of the city: $a^{*}=0$ (full dispersion).

Proof. In Baudewyns (2000), appendix, sections 8 and 9.

The dominant firm prefers to locate at the right end of the line in order to benefit from the best local environment while firm A's location depends crucially on the value of the relative transportation cost $(t / \alpha)$. Quite intuitively, as compared with the reference model, assuming the existence of some strong amenity advantage at the right end simply reinforces the desire of firm B to locate at that location. That is, the sum of the demand externality effect and the standard price competition (strategic) effect dominates the standard market area effect - which dictates firms to locate around the midpoint. ${ }^{8}$ The dominant firm has a higher markup over marginal cost except in the full agglomeration situation according to which both firms price at marginal cost. The intuitive explanation of result (i) is that consumers highly value amenities in eastern areas to such an extent that all the residents situated in the hinterland of A prefer to visit firm B. That is true even if A locates itself in a neighborhood close to $\mathrm{B}$ (still on the left of $\mathrm{B}$ ) and reduces its price to

${ }^{8}$ We mean by "standard" those effects in the reference model. For example, the amenity effect-through the ratio $\alpha / t$-reinforces or weakens the market area effect in the set-up above. After solving for price competition, this effect is given by:

$$
\frac{\delta D_{A}}{\delta a}=\frac{3-5 a-b}{6(1-b-a)}+\frac{\alpha / t}{6(1-b-a)}
$$

The first fraction is the (standard) market area effect in the reference model. For $a<\frac{1}{2}$, firm $\mathrm{A}$ is incited to move toward the geometric center $\left(x=\frac{1}{2}\right)$ in order to increase its market share. For $a>\frac{1}{2}$ (still $a<1-b$ ), these two effects are conflicting: on one hand, firm A wants to move westwards to be closer to the center of the distribution of households; on the other hand, the lower is $t / \alpha$, the higher is the proportion of households being attracted by eastern areas where the level of amenities is higher. 
unit cost. ${ }^{9}$ Since any firm can guarantee itself half of the market by locating at the east end of the city, this location is the only one surviving iterated weak dominance (IWD). We will extensively comment on the possibility of full agglomeration in subsection 4.1 below. As $\frac{t}{\alpha}$ rises, firm A balances the advantages of spatial isolation and those of being closer to the east end by choosing an intermediate location [result (ii)]. Finally, whenever the distribution of urban amenities is relatively flat (low $\alpha / t$ ), price competition becomes the strongest force, as in the no-amenity model [result (iii)].

\section{Symmetric triangular distribution of ameni- ties}

As emphasized in the first section, for European cities, it is more natural to hypothesize that the amount of urban amenities is maximum at the center of the geographic space. Therefore, suppose that the distribution of urban amenities is triangular, symmetric about the midpoint:

$$
f(x)=\left(1+\frac{\alpha}{4}\right)+\alpha\left|x-\frac{1}{2}\right|
$$

where $0<\alpha<4$, so that $f(x)>0$ at any location and the total cumulative distribution of amenities is normalized to 1 . Let us then distinguish two possible situations. First, assume that each firm locates on either side of the city $\left(a\right.$ and $\left.b \leq \frac{1}{2}\right)$. Then, the marginal consumer resides at the following location:

$$
\widehat{x}=\frac{p_{B}-p_{A}}{2 t(1-b-a)}+\frac{1-b+a}{2}-\frac{\alpha(b-a)}{2 t(1-b-a)}
$$

after substituting (11) into (3) and using $f(1-b)=f(b)$ from symmetry. Second, imagine that one firm - e.g., firm B - is situated between its rival and the city center: $a<1-b \leq \frac{1}{2}$. Then, plugging the amounts of amenities at respective locations into (3), we obtain exactly the same expression as in (10). ${ }^{10}$ It follows immediately that the expressions of profit functions

\footnotetext{
${ }^{9}$ The idea is also that B cannot commit itself to set a sufficiently high price that would allow A to attract some consumer(s).

${ }^{10}$ Indeed, the amount of amenities at each location is $\left(1-\frac{\alpha}{4}\right)+\alpha a$ and $\left(1-\frac{\alpha}{4}\right)+\alpha(1-b)$ respectively. As compared with the preceding section, for $a<1-b \leq \frac{1}{2}$, the change in the intercept of the amenity distribution - from $(1-\alpha / 2)$ to $(1-\alpha / 4)$ - has no impact on the determination of the marginal consumer's location.
} 
are exactly identical to those calculated in section 3. As compared with proposition 1 , the only change is the threshold value of $\frac{t}{\alpha}$ under which $\widehat{x}=0$ (see the next subsection). Therefore,

Result 1. For firm B, the midpoint dominates any location in the first half of the line.

More intuitively, the nature of spatial competition on the left side of the city is the same as the one depicted in figure 1. Consequently, it remains to solve the model for any $a$ and $b \in\left[0, \frac{1}{2}\right]$. Observe in (12) that, for a fixed transportation cost, the higher the slope of the amenity distribution, the higher the proportion of consumers patronizing the most centralized firm. Because the analysis is more intricate compared to proposition 1, we will split the presentation of the results into three subsections: in the following subsection, we consider very low values of $t / \alpha$; subsection 4.2 revisits the principle of maximum differentiation and, finally, subsection 4.3 completes the solution of the model by considering all the remaining intermediate values of $t / \alpha$ for which both asymmetric and symmetric equilibria emerge.

\subsection{Highly-centralized urban amenities: restoring the principle of minimum differentiation}

Let us consider a city characterized by a high concentration of urban amenities in central areas and a low transportation cost parameter, i.e. a city with a low $t / \alpha$. For $\frac{t}{\alpha} \leq \frac{1}{3}$, lemma 3 in the appendix of Baudewyns (2000) shows that if firm $\mathrm{A}$ is decentralized while its competitor is at the city center, then the former gets no demand for its product in any equilibrium of the last stage. The explanation is similar to the one given in section 3: the relative transportation cost is so weak that all the residents in the hinterland of $\mathrm{A}$ visit firm B, which is at the main urban site. That is true even if firm A locates itself in a urban neighborhood close to the center (still $a<\frac{1}{2}$ ) and reduces its price to unit cost. For $\frac{t}{\alpha} \leq \frac{1}{3}$, we also show in the appendix (Baudewyns, 2000) that any firm that is closer to the center is incited to relocate exactly at $\frac{1}{2}$ in order to benefit from the best local environment. Hence,

Proposition 2 For a symmetric triangular distribution of amenities and a very low relative transportation cost, the unique SPE (surviving IWD) 
exhibits a minimum differentiation of locations with both firms pricing at marginal cost:

$$
\frac{t}{\alpha} \leq \frac{1}{3} \quad \Rightarrow \quad a^{*}=b^{*}=\frac{1}{2} \quad \text { and } \quad p_{A}^{*}=p_{B}^{*}=0
$$

Proof. In Baudewyns (2000), appendix, subsections 10.1 and 10.2.

In other words, there exists a unique equilibrium in which minimum differentiation occurs with the Bertrand result. In real-world cities, products are slightly differentiated and a firm like A expects a small positive markup by choosing the central location. For highly-centralized amenities, the key of the principle of minimum differentiation is not a moderation of price competition. It is the desire of consumers to have access to the best local environment in the main city center to such an extent that no consumer would patronize a non-centrally located duopolist (given that its rival has chosen the city center).

For example, in most European cities McDonald's is sharing the fast food restaurants market with another competitor (e.g. Quick in Belgium and France) situated in general next door. ${ }^{11}$ Products are almost homogeneous, price competition is tough and, generally, both firms choose the same location. In middle-sized Belgian cities, the locational choices of the duopoly involves two competing units in the same central neighborhood (e.g., Bruges, Charleroi, Namur). This is also the case in central areas of Paris: for example at les Halles or at Jardins de Luxembourg/Panthéon, McDonald's is the next-door neighbor of Quick. In Brussels, both firms are exactly at the end of Chaussée d'Ixelles which can be viewed as an example of the so-called Hotelling main-street. Again, we argue that the reason for this pattern of locations is not a moderation of price competition through product differentiation - which is very low in that industry. It is instead the attractive force exercised by the concentration in central locations, of many other economic, social and cultural outside alternatives - what we have called urban amenities. $^{12}$

\footnotetext{
${ }^{11}$ This was the pattern of location in Belgium during the expansion stage of the hamburger restaurants sector between 1977 and 1983 (see Vlassenbroeck (1995) for a detailed empirical analysis). In 1983, from the 34 units-Quick or McDonald's-existing in this country, 23 were at the main central commercial site.

${ }^{12}$ For example, in the neighborhood of the park Jardins de Luxembourg, there is a cluster of movie theaters and other historical amenities such as museums and old buildings.
} 


\subsection{Relatively-flat distribution of amenities: revisiting the principle of maximum differentiation}

Consider now a city in which the transportation cost is high relatively to the concentration of urban amenities (low $\alpha / t$ ). In such a case, central locations are much less attractive and we can expect a high differentiation of locations. In particular, recall that as $\alpha \rightarrow 0$ our set-up tends to the reference model of d'Aspremont et al (1979). Consequently, there should exist a threshold value of $t / \alpha$ above which both firms differentiate maximally their locations. This is formally established in the following result.

Proposition 3 If the symmetric triangular distribution of urban amenities is flat relatively to the transportation cost, then the unique SPE exhibits a high (or even a maximum) differentiation of locations:

(i) $\frac{t}{\alpha} \geq 2 \quad \Rightarrow \quad a^{*}=b^{*}=0$

(ii) $\frac{4}{3}<\frac{t}{\alpha}<2 \Rightarrow 0<a^{*}=b^{*}<\frac{1}{8}=0.125$

Proof. In Baudewyns (2000), appendix, subsections 10.3, 10.4 and 10.5, and lemma 6.

In result (i), when the impact of amenities is very weak then price competition is the strongest force, as in the no-amenity case. Under product homogeneity, both firms locate as far from each other as possible in order to soften price competition. Doing so, our duopolists equally share the market and benefit from the monopoly power resulting from spatial isolation. This effect dominates the sum of the standard market area effect-which tells firms to locate near the center of the distribution of consumers - and the spatial demand externalities effect arising from the existence of urban amenities. In result (i), the equilibrium levels of price and profit are exactly the same as in the reference model (see Baudewyns (2000), appendix, subsection 10.3). In equilibrium (ii), the differentiation is not maximum since each firm tacitly chooses an inside (symmetric) suburban location, not too far from the endpoints - i.e., in the first and seventh eighths of the line respectively. ${ }^{13}$ Price competition is still fierce but firms choose to benefit from some urban amenities near respective borders.

\footnotetext{
${ }^{13}$ Interestingly enough, looking at symmetric equilibria, Neven (1986) obtains the same pattern of locations by considering concave distributions of consumers (not too much different from the uniform density) in the no-amenity reference model.
} 


\subsection{Intermediate values of $t / \alpha$ : asymmetric versus symmetric differentiation}

In what follows, we show that for intermediate values of the relative transportation $\operatorname{cost}\left(\frac{1}{3}<t / \alpha \leq \frac{4}{3}\right)$, firms more or less differentiate their locations, possibly in an asymmetric way. We call interior or inside location any location outside the borders and outside the city center as well (e.g. $0<a<\frac{1}{2}$ ). Solving the last case requires that we consider 3 types of candidates for an equilibrium:

(1) inside symmetric solutions of the system of first-order conditions $(0<$ $\left.a=b<\frac{1}{2}\right)$

(2) asymmetric pattern of locations with one firm at the midpoint whereas its rival locates at a more suburban site (possibly at one end)

(3) asymmetric candidates with one firm that is bound by one end of the line $(a=0$ or $b=0)$.

Any asymmetric equilibrium necessarily coexists with its "symmetric" that one simply obtains by interchanging $a$ and $b$, and exchanging A with B. For expositional purpose, we only present asymmetric equilibria in which $\mathrm{B}$ is the dominant firm and we proceed with the series of two propositions below.

Proposition 4 For $1.015<\frac{t}{\alpha}<\frac{4}{3}$, both symmetric and asymmetric SPE coexist : in the latter type of equilibrium, one firm locates at one end of the linear city $\left(a^{*}=0\right)$ while its rival, either locates at the center $\left(b^{*}=\frac{1}{2}\right)$, or departs from the center as the relative transportation cost rises $\left(\frac{t}{\alpha}>1.1984\right)$.

Proof. in Baudewyns (2000), appendix, lemma 5 and lemma 7 (subsection 10.5) and subsection 10.7.

Each retailer would like to be the centralized (dominant) firm in an asymmetric situation in order to benefit from the best local environment. ${ }^{14}$ Besides, using a "trembling hand" argument one can reasonably select asymmetric equilibria. Indeed, observe in figure 2, that for any small mistakes

\footnotetext{
${ }^{14}$ Formally, let $\Pi^{S}$ the common value of the profit in any symmetric equilibria and $\Pi_{A}^{N S}$ (repectively $\Pi_{B}^{N S}$ ) firm A's profit (respectively firm B's profit) in asymmetric equilibria. One can show that: $\Pi_{A}^{N S}<\Pi^{S}<\Pi_{B}^{N S}$.
} 


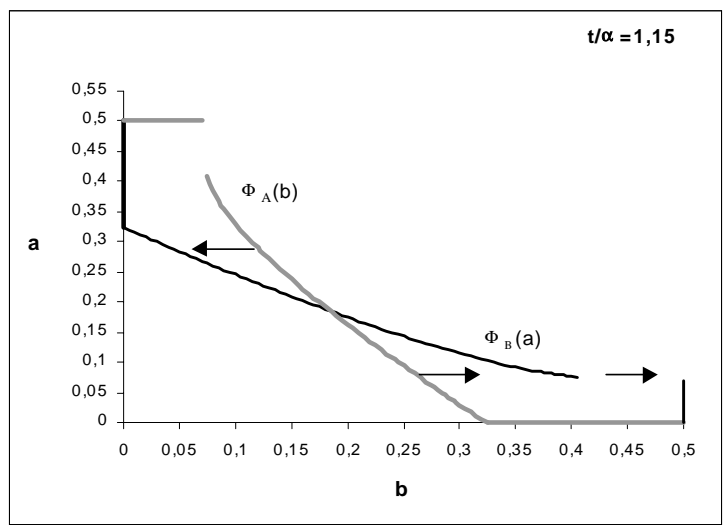

Figure 2: Best-reply functions in the location game $(1.015<t / \alpha<1.198375)$

or small deviation from the fixed point, the mirror game of best responses diverges to one of the axis $(a=0$ or $b=0)$. In this sense, asymmetric equilibria are the only "locally-stable" outcomes of the location game.

Turning now to the last case, and recalling proposition 2, one expects, quite intuitively, a weak differentiation of locations for $\frac{t}{\alpha}$ close to $\frac{1}{3}$ : this is formally shown in the following result.

Proposition 5 (Unique asymmetric outcome). For $\frac{1}{3}<\frac{t}{\alpha} \leq 1.015$, the unique outcome of the location-then-price game is an asymmetric differentiation of locations: one firm is at the center whereas its rival is more and more decentralized as the relative cost of transportation rises. For $\frac{t}{\alpha} \geq \frac{2}{3}$, the latter locates at one end of the line: $\left(a^{*}, b^{*}\right)=\left(0, \frac{1}{2}\right)$.

Proof. In Baudewyns (2000), appendix, lemma 8 and lemma 9 (subsection 10.6).

Again, each firm would like to be the one situated at the midpoint where the spatial distribution of amenities is maximum. As compared with the minimum differentiation outcome, the latter proposition shows that one firm is now pushed toward a more suburban location while its rival stays at the central site in order to benefit from the best local environment. The intuitive explanation for the non-existence of a symmetric equilibrium is the following: for any given symmetric location $a=b<\frac{1}{2}$, each firm is incited to relocate exactly at the midpoint because the positive amenity effect dominates the loss 
resulting from a fiercer price competition. Accordingly, only an asymmetric situation emerges as a stable outcome.

The intuition is also given in figure 7: whenever A moves towards the midpoint in the second quarter of the line $(a>0.2426)$ its profit first decreases with $a$ because of an intensified price competition ; for locations very close to the city center however, the amenity effect becomes the strongest force and firm A's payoff continuously increases as it moves closer and closer to the midpoint. In other words, firm A's profit function is not quasiconcave and best-reply functions exhibit some discontinuities as illustrated in figure 2 .

\begin{tabular}{|c|c|c|}
\hline$\frac{t}{\alpha} \in$ & Symmetric SPE locations & Asymmetric SPE locations \\
\hline $\left.0, \frac{1}{3}\right]$ & $\frac{1}{2}$ & - \\
\hline$\left[\frac{1}{3}, \frac{2}{3}\right]$ & - & $\left(0<\frac{\alpha}{3 t}-\frac{1}{2}<\frac{1}{2}, \frac{1}{2}\right)$ \\
\hline$\left[\frac{2}{3}, 1.015\right]$ & - & $\left(0, \frac{1}{2}\right)$ \\
\hline$[1.015,1.1984]$ & $0.167<\frac{\alpha}{2 t}-\frac{1}{4}<0.2426$ & $\left(0, \frac{1}{2}\right)$ \\
\hline$\left[1.1984, \frac{4}{3}[\right.$ & $0.125<\frac{\alpha}{2 t}-\frac{1}{4}<0.167$ & $\left(0,0.25<\Phi_{B}(0)<0.4584\right)$ \\
\hline$\left[\frac{4}{3}, 2\right]$ & $0<\frac{\alpha}{2 t}-\frac{1}{4}<0.125$ & - \\
\hline$[2,+\infty[$ & 0 & - \\
\hline
\end{tabular}

Table 1: all equilibrium locations (symmetric triangular amenity distribution)

All the pure-strategy equilibria in locations are presented in table 1. Having selected asymmetric equilibria, observe that we go from a symmetric to an asymmetric pattern of locations as $\frac{t}{\alpha}$ decreases near $\frac{4}{3}$. Although there is "a jump" in the spatial behavior of each firm (from 0.125 to 0 and from 0.125 to 0.25 respectively), the results are continuous in terms of spatial differentiation. ${ }^{15}$ This is illustrated in figure 3 where we have reversed the roles of $\mathrm{A}$ and $\mathrm{B}$. Intuitively, as the relative transportation cost decreases, demand externalities become the stronger force for firm A while firm B chooses to keep its distance in order to soften price competition. Note also that for $\frac{t}{\alpha} \approx 1.1984$, the dominant firm jumps from $0.542(=1-0.458)$ to the midpoint (firm A staying at one end of the city). Again, this illustrates the attractive force of urban amenities at the city center.

\footnotetext{
${ }^{15}$ For any $\frac{t}{\alpha} \gtrsim \frac{4}{3}$ we have $a^{*}=b^{*} \lesssim 0.125$, whereas for $\frac{t}{\alpha} \lesssim \frac{4}{3}: a^{*}=0, b^{*} \gtrsim 0.25$.
} 


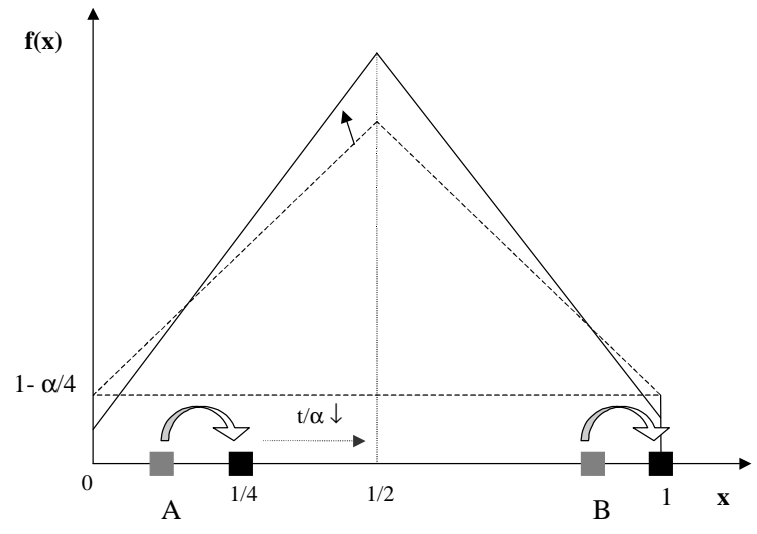

Figure 3: Asymmetric vs. symmetric equilibria

From table 1, one can also summarize all the results of the symmetric set-up as follows. As $t / \alpha$ decreases, we go from a symmetric to an asymmetric high differentiation of locations with the dominant firm locating in the third quarter of the city whereas its rival is pushed to the opposite border of the city. Below a certain level of the relative transportation cost, the dominant firm locates at the midpoint while its rival stays on its border. As $t / \alpha$ further decreases, the latter finds a compromise between the benefits of spatial isolation and the positive effects of amenities by departing from the outermost area to locate inside one half of the line. Finally, whenever $t / \alpha$ is very low, it meets the dominant firm at the main urban center where it does not earn supranormal profits but is able to attract a substantial share of the market.

The existence of asymmetric equilibria is one of the most striking results of this paper since, even though the set-up is perfectly symmetric, the existence of centralized amenities generates asymmetric firms' locations and consequently causes intra-urban inequalities. For example, for $\frac{t}{\alpha}=\frac{1}{2}$, one calculates $\left(a^{*}, b^{*}\right)=\left(\frac{1}{6}, \frac{1}{2}\right)$ and $D_{A}^{*} \simeq 0.11, D_{B}^{*} \simeq 0.89$. In other words, not everyone has access to the same amount of urban amenities. In particular, consumers on the right side of the city - plus those situated between 0.11 and 0.5 - when shopping at the centralized site, can consume in one single trip a large amount of densely located urban amenities (e.g. public services). This is obviously not the case for the $11 \%$ of the population residing in the western 
fringe area. Notice also the fact that some consumers in the close hinterland of A prefer to shop to firm B at the city center: $\widehat{x}=0.11<a^{*}=\frac{1}{6}$.

This also brings us to the question of the impact of a change in the relative transportation cost $\left(\frac{t}{\alpha}\right)$ on social welfare through possible relocation decisions of firms. Two different kinds of public policies can result in a decrease of $\frac{t}{\alpha}$ : either, the city planner decides to concentrate more amenities in central areas, or he (or she) aims to lower per unit transportation costs. It follows that urban policies aiming to decrease the transportation cost - although welfare improving (see the next section) - could in fact, as in economic geography, induce more spatial inequalities through pernicious relocation of firms. ${ }^{16}$ Consider indeed the first half-segment and a consumer close to the city center. For $\frac{t}{\alpha}=1.34$, firms are symmetrically located about the center: $a=b \approx 0.124$. Consider also the consumer residing at $x=0.125$. Clearly, both consumers patronize firm A. Now, imagine that the city planner decides to expand the total capacity of the urban transportation system, so that the relative transportation cost is reduced to $\frac{t}{\alpha}=1$. Then, in equilibrium, firm B relocates at the city center whereas firm A is pushed towards the left border. The centrally-located consumer now obviously patronizes firm B while our consumer situated at $x=0.125$ visits the outermost commercial site. Clearly, the former benefits from more urban life opportunities incurring a smaller travel cost while the situation becomes conversely worse for the latter.

\section{$5 \quad$ Welfare analysis}

In the reference model, the central planner chooses $a=\frac{1}{4}$ and $1-b=\frac{3}{4}$ as socially optimal locations. These locations minimize the consumers' average transportation cost since for inelastic aggregate demands, pricing decisions do not affect the total welfare. ${ }^{17}$ Let us restrict ourselves to the symmetric amenity distribution case and let $T$ denote the social transportation cost incurred by the population of consumers as a whole. ${ }^{18}$ Let, also, $W$ denote the total welfare defined as the sum of firms' profits and consumers surplus.

\footnotetext{
${ }^{16}$ In a shipping model à la Hotelling, Combes and Linnemer (2000) also obtain asymmetric results when analyzing the effects of a new transportation infrastucture (i.e. two symmetrically-located airports) on firms' locations.

${ }^{17}$ See Tirole, 1988, p. 282.

${ }^{18} T=\int_{0}^{D_{A}} t(x-a)^{2} d x+\int_{D_{A}}^{1} t(1-b-x)^{2} d x$.
} 
After some manipulations, and by symmetry of the amenity distribution, we obtain:

$$
W=\bar{u}+\int_{0}^{D_{A}} f(a) d x+\int_{D_{A}}^{1} f(b) d x-T
$$

The total welfare is thus simply the sum of the reservation price and the total value of amenities consumed at respective commercial sites net of the social transportation cost.

What is the impact of the existence of some (symmetric) distribution of amenities on the pattern of locations chosen by a city planner ? Intuitively, the lower $t / \alpha$ is, the more centralized locations should be as compared with the aforementioned results of the no-amenity model. One can thus expect both firms in the second and third quarter of the linear city. This is formally established in the following result, looking at symmetric equilibria (standard $)^{19}$ :

Proposition 6 As $t / \alpha$ decreases, the symmetric locations chosen by a city planner are more and more centralized, in the second and third quarter of the line respectively:

$$
\begin{array}{cc}
\widehat{a}=\widehat{b}=\frac{1}{2} & \text { for } t \leq 2 \alpha \\
\frac{1}{4}<\widehat{a}=\widehat{b}=\frac{\alpha}{2 t}+\frac{1}{4}<\frac{1}{2} & \text { for } t>2 \alpha
\end{array}
$$

Proof. In Baudewyns (2000), appendix, subsection 10.8.

For example, for $t=2 \alpha$, the socially-optimal outcome should be both firms at the center whereas, in a laissez-faire world, firms maximally differentiate their locations (recall proposition 3). For, $1.015<\frac{t}{\alpha} \leq 2$, one observes in table 1 that locations differentiation is $0.25<1-a^{*}-b^{*}<0.5$ whereas again, from the welfare point of view, it should be both firms at the midpoint. To sum up,

Corollary 1 For $t>\frac{\alpha}{3}$, any market outcome, symmetric or asymmetric, exhibits an excessive differentiation of locations.

\footnotetext{
${ }^{19}$ One can imagine that firms are forced to price at marginal cost. Alternatively, one can also suppose that the social planner is concerned with equity: the population residing in the first half-segment and the population in the second half should get both the same net consumer surplus.
} 
On the other hand, recalling proposition 2 , we get the quite intuitive following result:

Corollary 2 If urban amenities are relatively highly-centralized (i.e., $\frac{\alpha}{3}>t$ ) then the non-cooperative decisions of firms to locate together at the midpoint is socially optimal.

\section{Conclusion}

In this paper, we have shown that the firms' tendency to differentiate their locations depends strongly on the urban structure in which they will operate. In fact, urban economists should not enunciate any principle of maximum (or minimum) differentiation. In real-world cities, all will depend on the existing spatial agglomeration of various economic, cultural and social opportunities.

In particular, for a highly-concentrated amenity distribution and a given low transportation cost, the key of the principle of minimum differentiation is the non-existence of some positive demand outside the main urban center that results from the desire of residents to consume all sorts of urban amenities at that location. When both firms are not allowed to adopt any mechanism that relaxes price competition, minimum differentiation of locations occurs with both firms pricing at marginal cost, in contrast to mainstream results in the literature. In this sense, our paper reconciles Hotelling and Bertrand in the context of spatial demand externalities within a noncooperative location-then-price game. This paper has formally shown that although price competition is indeed a centrifugal force, firms selling identical products may agglomerate even though they both price at (or close to) marginal cost in the last stage.

The second striking result of our shopping model is that asymmetric equilibria emerge for intermediate values of $\frac{t}{\alpha}$ even though the set-up is perfectly symmetric: one firm locates near (or at) the center of the amenity distribution whereas its rival chooses a more suburban location, possibly at one end of the city. The latter balances the oligopolistic advantages of spatial isolation and those of being closer to the main central area. This result raises the question of intra-urban inequalities. Indeed, a minority of residents are induced to shop at the decentralized firm and, as a result, encounter in one single trip less urban life opportunities than do the rest of the city population. The former would prefer a more centralized pattern of firms' locations 
and a lower transportation cost. It also follows that urban policies aiming to decrease the transportation cost variable $t$ - or city planning decisions to centralize urban amenities - may be welfare improving but at the expense of more spatial inequalities through pernicious relocation of firms.

The existence of asymmetric equilibria is even more problematic if the city is divided into two distinct juridictions, the left half-segment and the right half-segment. If the two local governments independently decide the optimal spatial distribution of public amenities, they will probably not concentrate them near the midpoint. Indeed, if a local planner locates its amenities near the center, inducing at least one firm at the central site (i.e., at the fringe of its juridiction) then some potential benefits will be received by the residents of the other juridiction who patronize the central firm. Hence, without an appropriate coordination scheme, the centralization of amenities will not be decided by the two local governments. This would clearly lead to inefficient locational choices but inequalities would be reduced as compared to laissezfaire. This should be the subject of future research.

Another reason for decentralizing public amenities is congestion problems at the site level (think of overcrowded parks, museums). One simple way to incorporate congestion in the analysis is to substract from the social welfare, a social cost positively related to the number of consumers visiting respective marketplaces (e.g. the cost of maintenance of parks, streets, and so on). A low transportation cost inducing the entire population of consumers to patronize firms at the same central site could not be necessarily optimal from the welfare point of view because of a high congestion cost.

\section{$7 \quad$ References}

d'Aspremont C., Gabszewicz J.J. and Thisse J.-F. (1979), "On Hotelling's Stability In Competition", Econometrica, 47: 1145-1150.

Baudewyns D. (2000), "Spatial Competition within Urban Areas: Hotelling and Bertrand Reconciled", Working Paper $n^{\circ} 390$, April.

Brueckner J.K., Thisse J.F. and Zenou Y. (1998), "Why is central Paris rich and downtown Detroit poor? An amenity-based theory", European Economic Review, 43 (1): 1-208.

Combes P. Ph., Linnemer L. (2000), "Intermodal competition and regional inequalities", Regional Science and Urban Economics.

de Palma A., Ginsburgh V., Papageorgiou Y.Y. and Thisse J.-F. (1985), 
"The Principle of Minimum Differentiation Holds Under Sufficient Heterogeneity", Econometrica, 53 (4): 767-781.

Friedman J. W. and Thisse J. F. (1993), "Partial Collusion Fosters Minimum Product Differentiation", Rand Journal of Economics, 24: 631-645.

Gabszewicz J.J. and Thisse J.-F. (1992), "Location" in Auman and Hart eds., Handbook of Game Theory with Economic Applications, Volume 1, Amsterdam, North-Holland.

Jehiel P. (1992), "Product Differentiation and Price Collusion", International Journal of Industrial Organization, 10: 663-641.

Mai C.-C., Peng S. (1999), "Cooperation vs. competition in a spatial model", Regional Science and Urban Economics, 29: 463-472.

Neven (1986), "On Hotelling's competition with non-uniform customer distributions", Economics Letters, 21:121-126.

Quinzii M. and Thisse J.-F. (1990), "On the Optimality of Central Places", Econometrica, 58: 1101-1119.

Rhee B., de Palma A., Fornell C. and Thisse J.-F. (1992), "Restoring the Principle of Minimum Differentiation in Product Positioning", Journal of Economics and Management Strategy, 1: 475-505.

Stahl K. (1982), "Location and Spatial Theory with Nonconvex Transportation Cost Schedules", Bell Journal of Economics, 13: 575-582.

Stahl K. (1987), "The Theory of Urban Business Location", in E. S. Mills ed.: $759-820$.

Stahl K. (1995), "Towards a microeconomic theory of the retailing sector", paper presented at ECARE, Brussels.

Tabuchi, T., Thisse, J.-F. (1996), "Asymmetric equilibria in spatial competition", International Journal of Industrial Organization, 13:213-227.

Thill J.C., I. Thomas I. (1987), "Toward Conceptualizing Trip Chaining: A Review", Geographical Analysis, 19, 1-17.

Tirole J. (1988), The Theory of Industrial Organization, the MIT Press, Cambridge, Massachusetts.

Vlassenbroeck (1995), "The geography of a special case of the out-ofhome eating industry in Belgium: the sector of hamburger restaurants", Revue Belge de Géographie, 59, tome 2: 317-324.

Zhang Z. J. (1995), "Price-Matching Policy and the Principle of Minimum Differentiation", Journal of Industrial Economics, 43 (3): 287-300. 